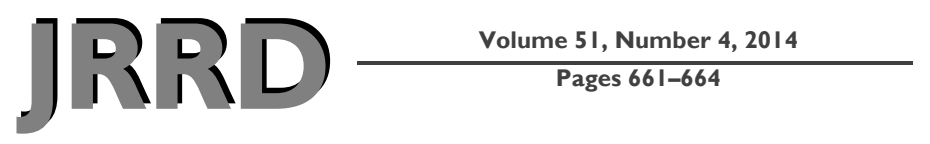

\title{
Botulinum toxin injection for bruxism associated with brain injury: Case report
}

\author{
Serdar Kesikburun, MD; ${ }^{*}$ Rıdvan Alaca, MD; Berke Aras, MD; İlknur Tuğcu, MD; Arif Kenan Tan, MD \\ Department of Physical Medicine and Rehabilitation, Gülhane Military Medical Academy, Turkish Armed Forces \\ Rehabilitation Center, Ankara, Turkey
}

\begin{abstract}
Bruxism is involuntary grinding of the teeth and can occur as a complication of brain injury. If untreated, bruxism can lead to severe occlusal trauma. Herein, we present a patient with traumatic brain injury and nocturnal bruxism that was treated with botulinum toxin injection. A $21 \mathrm{yr}$ old male patient with traumatic brain injury from a car accident was admitted to our inpatient rehabilitation unit. He had a history of coma for $2 \mathrm{wk}$ in the intensive care unit. The initial cranial computed tomography scan indicated a superior thalamic hemorrhage. On admission to our department 3 mo postinjury, his mental status was good and he was able to walk without assistance, but he had mild ataxia. He complained about severe teeth grinding at night, which began 2 mo postinjury. Botulinum toxin-A was injected into the masseter muscles ( $20 \mathrm{U}$ in each muscle) and temporalis muscles (15 $\mathrm{U}$ in each muscle) bilaterally. A decrease in bruxism was reported within $3 \mathrm{~d}$. Clinical improvement persisted at assessment 4 mo posttreatment. Botulinum toxin injection can be used as an effective treatment for bruxism associated with brain injury.
\end{abstract}

Key words: botulinum toxin, bruxism, bruxism treatment, case report, complication, masseter muscle, temporalis muscle, tooth clenching, tooth grinding, traumatic brain injury.

\section{INTRODUCTION}

Bruxism is a form of dystonia characterized by involuntary grinding or clenching of the teeth. Bruxism can occur while awake (diurnal bruxism) or during sleep (nocturnal bruxism) [1]. The incidence of bruxism in the general population is reported to be 21 percent, and it occurs with equal frequency in males and females but is more common in the younger population [2]. In addition, bruxism can occur as a complication of brain injury. Bruxism can lead to masseter hypertrophy, headache, periodontal disease, temporomandibular joint destruction, and tooth wear [3]. The traditional treatment for bruxism includes intraoral appliances, pharmacologic agents such as benzodiazepine, and behavioral modification techniques, but no intervention is reported to be completely effective [4]. It was hypothesized that the masseter and temporal muscles could play a role in the pathogenesis of bruxism and that botulinum toxin could be used to decrease hyperactivity in these muscles. Herein, we present a patient with bruxism following traumatic brain injury who was successfully treated with botulinum toxin-A (BTX-A).

\section{CASE REPORT: METHODS AND RESULTS}

A 21 yr old male patient with traumatic brain injury from a car accident was admitted to our inpatient rehabilitation unit. He had a history of coma for $2 \mathrm{wk}$ in the intensive care unit. The initial cranial computed tomography

\footnotetext{
Abbreviations: BTX-A = botulinum toxin-A.

*Address all correspondence to Serdar Kesikburun, MD; TSK Rehabilitasyon Merkezi 06530 Bilkent/ANKARA, Turkey; +0-312-2911707; fax +0-312-2911009.

Email: serdarkb@gmail.com

http://dx.doi.org/10.1682/JRRD.2013.10.0218
} 
scan indicated a superior thalamic hemorrhage. On admission to our department 3 mo postinjury, his mental status was good and he was able to walk without assistance, but he had mild ataxia. He complained about severe teeth grinding during the night that began 2 mo postinjury and was observed by his relatives. Botulinum toxin was suggested to the patient to treat bruxism.

BTX-A was injected into the patient's masseter and temporalis muscles bilaterally. The dose of BTX-A injected into each masseter and temporalis muscle was $20 \mathrm{U}$ and $15 \mathrm{U}$, respectively, with a dilution of $1 \mathrm{~mL}$; a $1 \mathrm{~mL}$ insulin syringe and a $30 \mathrm{G}$ needle were used with a single injection point. The injection sites were $3 \mathrm{~cm}$ superior to the temporomandibular joint for the temporalis muscles and $3 \mathrm{~cm}$ inferior to the temporomandibular joint for the masseter muscles (Figure). The patient tolerated the procedure well and there was no erythema, swelling, bleeding, infection, or muscle atrophy at the injection site and no drooling. Jaw clenching and tooth grinding decreased $3 \mathrm{~d}$ after the treatment. Assessment at $4 \mathrm{wk}$ posttreatment showed that clinical improvement persisted.

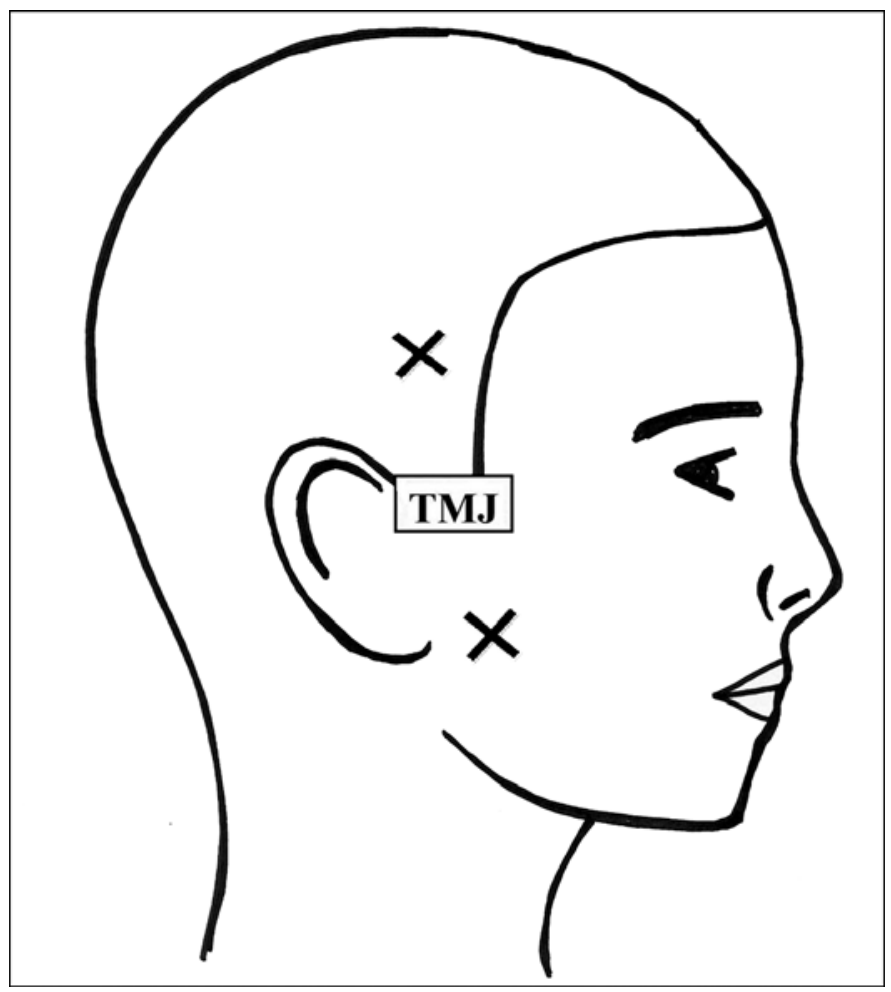

Figure.

Injection sites for massater and temporalis muscles were $3 \mathrm{~cm}$ superior and inferior to temporomandibular joint (TMJ).

\section{DISCUSSION}

The etiology of nocturnal bruxism is not well understood and is associated with numerous causes, including genetic factors, trauma, drugs (L-3,4-dihydroxyphenylalanine, selective serotonin reuptake inhibitors, and propranolol), and neurologic and psychiatric diseases [5]. Psychosocial factors, such as stress and behavioral changes, are typically reported in association with bruxism. Various treatments have been reported for bruxism, including intraoral guards, drugs (benzodiazepines, dopamine agents, antidepressants, muscle relaxants, and beta blockers), botulinum toxin injection, dental surgery, psychosocial interventions (i.e., relaxation techniques, stress management, and behavioral modification), physical therapy (isokinetic stretching exercises and mandibular exercises), manual therapy, and electrophysical modalities (ultrasound, shortwave diathermy, low-intensity laser therapy, transcutaneous electrical stimulation, biofeedback training, and muscular awareness relaxation therapy) [6-8]; however, there is no consensus concerning which is most effective.

Botulinum toxin is a neurotoxin produced by the bacterium Clostridium botulinum. There are 7 different forms of the neurotoxin, ranging from types A through $\mathrm{G}$, with type A being the most commonly used for therapeutic applications. BTX-A works by blocking the release of acetylcholine at the neuromuscular junction. The toxin binds to cholinergic nerve terminals and proteolytically inactivates SNAP-25, a synaptosomal-associated protein utilized in synaptic vesicle fusion with the nerve terminal membrane. Then, a decrease in the frequency of acetylcholine released at the synaptic cleft causes temporary muscle paralysis. Weakness of targeted muscles usually lasts between 1 and 6 mo [9].

The side effects of botulinum toxin administration are usually minor and temporary. The primary side effects are paralysis of the wrong muscle group and allergic reactions due to the chemical structure of the molecule. Most of the studies we reviewed reported no adverse effects following treatment of bruxism with BTX-A other than predictable reactions, such as transient swelling at the injection site, low-grade fever, and soreness [10]. In the presented case, no complications of any kind occurred.

Generally, in the treatment of bruxism both the masseter and temporalis muscles are assessed during clinical evaluations and injected with BTX-A bilaterally. Usually, the total dose range is 50 to $200 \mathrm{U}$ with $1 \mathrm{~mL}$ dilution via 
2 to 3 sites of injection [11-12]. In the presented case, BTX-A was injected into each masseter and temporalis muscle on both sides via a single injection point (total dose: $70 \mathrm{U}$ ), resulting in clinical improvement.

\section{CONCLUSIONS}

In conclusion, bruxism can occur as a complication following traumatic brain injury. BTX-A injection into the masseter and temporalis muscles could be used to treat bruxism associated with traumatic brain injury.

\section{ACKNOWLEDGMENTS}

\section{Author Contributions:}

Study concept and design: S. Kesikburun, R. Alaca.

Acquisition of data: S. Kesikburun, B. Aras.

Analysis and interpretation of data: İ. Tuğcu, A. K. Tan.

Critical revision of manuscript for important intellectual content:

A. K. Tan, R. Alaca.

Administrative, technical, or material support: B. Aras.

Study supervision: R. Alaca.

Financial Disclosures: The authors have declared that no competing interests exist.

Funding/Support: This material was unfunded at time of manuscript preparation.

Additional Contributions: Dr. Tuğcu is now with İncek Physical Therapy and Rehabilitation Hospital, Ankara, Turkey.

Institutional Review: The patient provided informed consent. Participant Follow-Up: The authors plan to inform the participant of the publication of this study.

\section{REFERENCES}

1. Koyano K, Tsukiyama Y, Ichiki R, Kuwata T. Assessment of bruxism in the clinic. J Oral Rehabil. 2008;35(7):495-508. [PMID:18557916] http://dx.doi.org/10.1111/j.1365-2842.2008.01880.x

2. Reding GR, Rubright WC, Zimmerman SO. Incidence of bruxism. J Dent Res. 1966;45(4):1198-1204. [PMID:5224088] http://dx.doi.org/10.1177/00220345660450042701

3. See SJ, Tan EK. Severe amphethamine-induced bruxism: Treatment with botulinum toxin. Acta Neurol Scand. 2003; 107(2):161-63. [PMID:12580870] http://dx.doi.org/10.1034/j.1600-0404.2003.02086.x

4. Okeson JP. The effects of hard and soft occlusal splints on nocturnal bruxism. J Am Dent Assoc. 1987;114(6):788-91. [PMID:3475357]
5. Lobbezoo F, Van Der Zaag J, Naeije M. Bruxism: Its multiple causes and its effects on dental implants - an updated review. J Oral Rehabil. 2006;33(4):293-300.

[PMID: 16629884] http://dx.doi.org/10.1111/j.1365-2842.2006.01609.x

6. Macedo CR, Machado MA, Silva AB, Prado GF. Pharmacotherapy for sleep bruxism. Cochrane Database Syst Rev. 2006(1):CD005578.

7. Lee SJ, McCall WD Jr, Kim YK, Chung SC, Chung JW. Effect of botulinum toxin injection on nocturnal bruxism: A randomized controlled trial. Am J Phys Med Rehabil. 2010;9(1):16-23. [PMID:19855255] http://dx.doi.org/10.1097/PHM.0b013e3181bc0c78

8. Quinn JH. Mandibular exercises to control bruxism and deviation problems. Cranio. 1995;13(1):30-34. [PMID:7585999]

9. Dolly O, O'Sullivan GA, Mohammed N, Foran PG, Lawrence GW, Lisk G, Meunier FA, dePaiva A. Features influencing botulinum toxin-induced nerve sprouting and recovery from poisoning. Mov Disord. 2000;15:6.

10. Gormley M, Herring G, Gaebler-Spira D. The use of botulinum toxin in children: A retrospective study of adverse reactions and treatment of idiopathic toe-walking. Eur $\mathbf{J}$ Neurol. 1997;4:S27.

11. Ivanhoe CB, Lai JM, Francisco GE. Bruxism after brain injury: Successful treatment with botulinum toxin-A. Arch Phys Med Rehabil. 1997;78(11):1272-73. [PMID:9365360] http://dx.doi.org/10.1016/S0003-9993(97)90343-9

12. Santamato A, Panza F, Di Venere D, Solfrizzi V, Frisardi V, Ranieri M, Fiore P. Effectiveness of botulinum toxin type A treatment of neck pain related to nocturnal bruxism: A case report. J Chiropr Med. 2010;9(3):132-37. [PMID:22027036] http://dx.doi.org/10.1016/j.jcm.2010.04.004

Submitted for publication October 9, 2013. Accepted in revised form December 5, 2013.

This article and any supplemental material should be cited as follows:

Kesikburun S, Alaca R, Aras B, Tuğcu İ, Tan AK. Botulinum toxin injection for bruxism associated with brain injury: Case report. J Rehabil Res Dev. 2014;51(4):66164.

http://dx.doi.org/10.1682/JRRD.2013.10.0218

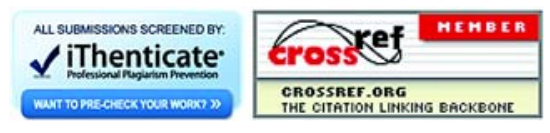


